Research Article

\title{
Impact of Particle Sizes on Flow Characteristics of Slurry Pump for Deep-Sea Mining
}

\author{
Runkun Wang, ${ }^{1}$ Yingjie Guan, ${ }^{2}$ Xing Jin, ${ }^{2}$ Zhenji Tang, ${ }^{1}$ Zuchao Zhu, ${ }^{1}$ and Xianghui Su $\mathbb{I D}^{1}$ \\ ${ }^{1}$ The Province Key Lab of Fluid Transmission Technology, Zhejiang Sci-Tech University, Hangzhou 310018, China \\ ${ }^{2}$ State Key Laboratory of Deep Sea Mineral Resources Development and Utilization, \\ Changsha Institute of Mining and Metallurgy, Changsha 410006, China \\ Correspondence should be addressed to Xianghui Su; suxianghui@zstu.edu.cn
}

Received 22 November 2020; Revised 17 December 2020; Accepted 26 February 2021; Published 5 March 2021

Academic Editor: Ling Zhou

Copyright ( $\odot 2021$ Runkun Wang et al. This is an open access article distributed under the Creative Commons Attribution License, which permits unrestricted use, distribution, and reproduction in any medium, provided the original work is properly cited.

\begin{abstract}
As the core device of the deep-sea mining transport system, the slurry pump and its internal solid-liquid two-phase flow are extremely complicated; especially, the migration characteristics of particles have a great influence on the flow and wear of the pump. In order to grasp the particle motion law inside the slurry pump, this paper took into consideration the collision effects of the particles with particles and particles with walls and calculated the unsteady flow of the solid-liquid two-phase by CFD-DEM coupling algorithm. Then, the focus was put on the spatial distribution and movement characteristics of different particle diameters (namely, $5 \mathrm{~mm}, 10 \mathrm{~mm}$, and $15 \mathrm{~mm}$, while volume concentration $\mathrm{Cv}$ is constant $5 \%$ ). The results show that the stratification phenomenon gradually disappears with the increase of particle diameter, and the intensity and scale of the vortex in the guide vane also increase obviously. Besides, as the particle diameter increases, the velocity changes more drastically, and the intensity and scale of the vortex increase significantly. Under low concentration conditions, the presence of particles has a limited influence on the hydraulic performance of the pump. By comparing with the experimental results, the simulation results are in good agreement with it, which proves that the CFD-DEM simulation in this paper is effective, and the conclusions can provide theoretical support for the design and analysis of the slurry pump in engineering application.
\end{abstract}

\section{Introduction}

With the depletion of terrestrial mineral resources, countries around the world have turned their future development focus toward the development of efficient combustion technology and utilization of deep-sea mineral resources [1]. At present, the most promising mining solution for commercial mining is the pipeline lifting system [2,3], as shown in Figure 1. The ore particles are collected by the mining vehicle on the bottom of the sea and reach the midtransferring buffer through the flexible pipe. And then, the ore particles would be raised from the midtransferring buffer, after remixing the ore particle volume concentration, to the water surface test vessel by the slurry pump and pipeline lifting system. The slurry pump is the only power device of this system as shown in Figure 2. Actually, it is easy to get blocked in case of a locally high concentration of ore particles, because of its complex hydraulic structure.
Therefore, the inside flow profile and particle movement are rather important, since its performance, operational stability, and reliability determine the efficiency and lifetime of the whole system. Over the past few decades, countries around the world have conducted many studies and sea test on the slurry pump and encountered the above problems. The pump developed by KSB Co. Ltd. in Germany [4] has serious wear on the flow components, and later the pumps developed by Japan [5] and South Korea [6, 7] come across a different degree of local particle blockage. In Changsha of China $[8,9]$, its slurry pump is tested during the sea trial and also a slight backflow blockage problem is found. To sum up, the slurry pump developed at home and abroad inevitably has the problems of insufficient overcurrent capacity, easy wear, and easy blockage. It is directly related to the flow pattern of the particle group, the spatial and temporal distribution of the particles, and the dynamic migration. In order to solve the above engineering problems, it is necessary 


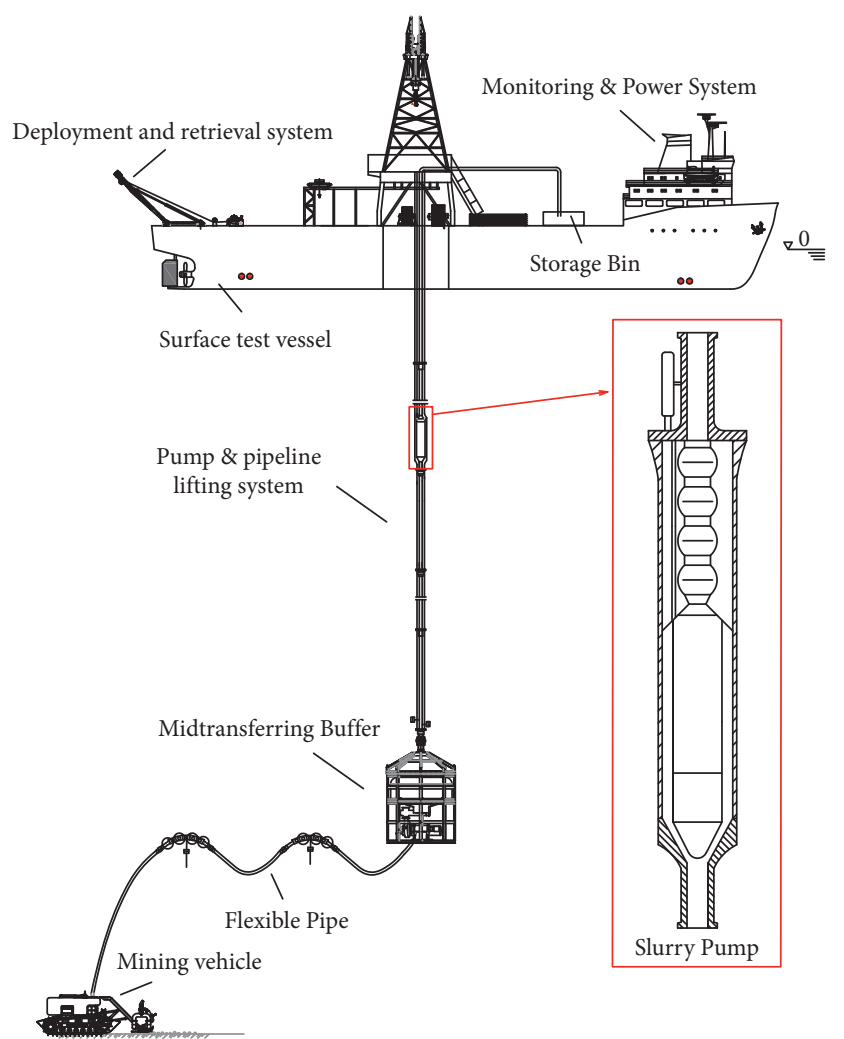

Figure 1: Deep-sea mining system.

to study the law and mechanism of the particle-water twophase flow in the slurry pump. Another important issue is the influence from the diameter of the particle, since it is necessary to determine what particle size is suitable for pump pipe transportation, which is related to the overall energy consumption and the cost of crushing and ore recovery. Yet it is still a vague understanding up to now.

The current research on slurry pumps is mainly based on the traditional solid-liquid two-phase flow model. Zeng et al. [10] and $\mathrm{Xu}$ et al. [11] used the two-fluid model (TFM) and discrete particle model (DPM) to analyse the influence of different pump's working parameters and particle-phase parameters on the performance of the slurry pump, respectively. However, the two-fluid model is a model that equates a solid particle to a pseudofluid for calculation. The solid term of the model is quite different from the actual physical state, so its calculation result also has a significant deviation from the actual situation. Similarly, the traditional two-phase flow model does not consider the force between particles, so there are certain limitations between particle distribution and motion states. The CFD-DEM coupling model inherits the advantage of the DPM model to treat particles as discrete phase and fluid as the continuous phase and considers the interaction between particles. Therefore, the model can directly improve the accuracy of the simulation. Huang et al. [12], Liu [13], and Gao [14] used the CFD-DEM coupling model to study the effect of particle motion law and particle properties on the solid-liquid two-phase pump. Li $[15,16]$ discussed the influence of the rotation speed and reflux of the slurry pump for the pump's working performance. At present,

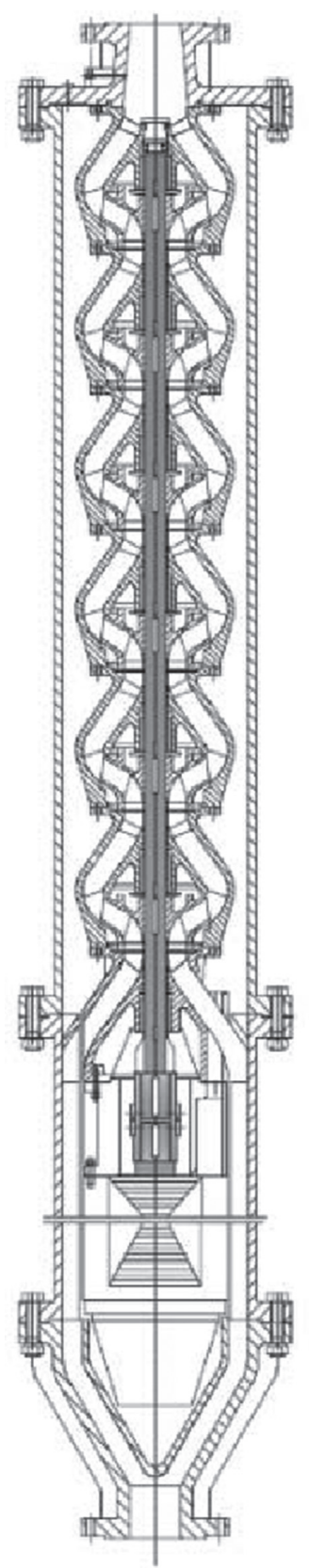

FIGURE 2: Structure of ore slurry pump for slurry.

there are not many pieces of research on the domain of the slurry pump concerning the application of CFD-DEM coupling methods, and the detail of the internal two-phase flow is not clear enough. Therefore, this paper used the CFD-DEM coupling model to analyse the particle movement characteristics in the slurry pump and the influence of particle diameters on the flow characteristics of the pump and provided a theoretical basis for the future development of slurry pumps.

\section{Models}

2.1. Mathematical Models. The solution strategy of the CFDDEM coupling method is that the CFD solves the continuous phase, and the DEM solver solves the discrete phase, so the 
CFD-DEM solution is divided into three parts: continuous phase solution, discrete phase solution, and coupling between two phases.

The solution of the fluid continuous phase mainly applies the continuity equation and momentum equation.

The continuity equation can be defined as

$$
\frac{\partial \rho}{\partial t}+\frac{\partial}{\partial x_{i}}\left(\rho v_{i}\right)=0
$$

where $\rho$ is the fluid density, $t$ is the time, and $v_{i}$ is the component of the velocity vector in the $i$ direction of the Cartesian coordinate system.

The conservation equation of momentum can be set to

$$
\frac{\partial}{\partial t}\left(\rho v_{i}\right)+\frac{\partial}{\partial x_{i}}\left(\rho v_{i} v_{j}\right)=-\frac{\partial P}{\partial x_{i}}+\frac{\partial \tau_{i j}}{\partial x_{j}}+\rho g_{i}+F_{i},
$$

where $P$ is the static pressure, $g_{i}$ and $F_{i}$ are the gravity and external volumetric forces in the $i$ direction of the Cartesian coordinate system, respectively, and $\tau_{i j}$ is the viscous stress tensor.

The discrete phase is solved by the contact model, and the acceleration of particles is calculated by Newton's second law, and then the velocity and displacement of particles are updated. The corresponding conservation equations of momentum and angular momentum are as follows:

$$
\begin{aligned}
m_{i} \frac{\mathrm{d} v_{i}}{\mathrm{~d} t} & =\sum_{j}\left(F_{n, i j}+F_{\tau, i j}\right)+F_{f p, i}+m_{i} g, \\
\frac{\mathrm{d}}{\mathrm{d} t} I_{i} \omega_{i} & =\sum_{j}\left(r_{i} \times F_{\tau, i j}+M_{i}\right),
\end{aligned}
$$

where $F_{n, i j}$ is the normal contact force between the particle $i$ and the particle $j, F_{\tau, i j}$ is the stress contact force, $I_{i}$ is the moment of inertia of the particle $i, F_{f p, i}$ is the force from the liquid phase relative to the particle $i$, and $M_{i}$ is the rolling friction torque of the particle $i$.

As is shown in Figure 3, the key to CFD-DEM coupling [12] lies in the data exchange between CFD solver and DEM solver. In each time step, the CFD solver first calculates the continuous phase flow field to convergence. Then, the simulation results of the continuous phase in the grid element are transferred to the DEM solver to calculate the forces on the particles, and the forces are substituted into the particle momentum equation to solve the position and velocity of the separated phase. After the DEM iterative calculation, the porosity between particles is estimated and transferred and forces back to the CFD solver. And then, the CFD solver uses these data to solve and revise the continuous phase flow field to the next time step.

2.2. Geometric Model. According to the working condition parameters of the slurry pump in China's slurry research project, the slurry model pump is designed with a similar principle. The specific speed $\left(n_{s}=102.17\right)$ of the model pump is the same as that of the prototype pump which is determined from equation (4). The basic parameters of the

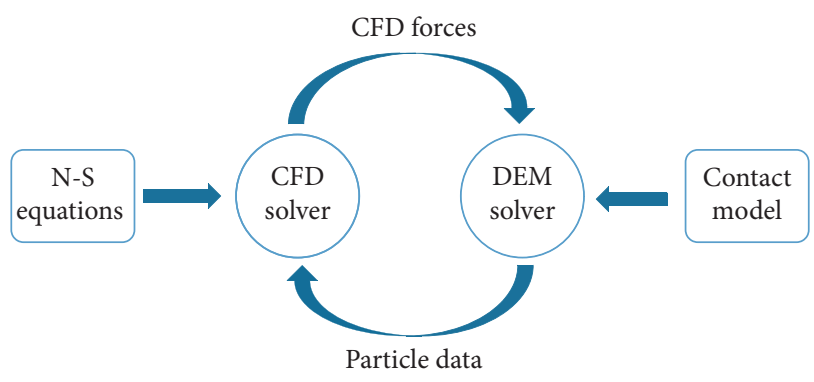

FIgUre 3: CFD-EDM coupling.

TABLE 1: Main geometric parameters of the model pump.

\begin{tabular}{lccc}
\hline \multicolumn{1}{c}{ Impeller parameters } & \multicolumn{2}{c}{ Guide vane parameters } \\
\hline Inlet diameter $(\mathrm{mm})$ & 135 & Inlet diameter $(\mathrm{mm})$ & 276 \\
Outlet diameter $(\mathrm{mm})$ & 272 & Inlet width $(\mathrm{mm})$ & 26 \\
Outlet width $(\mathrm{mm})$ & 25 & Outlet diameter $(\mathrm{mm})$ & 135 \\
Number of blades & 4 & Number of blades & 5 \\
Inlet blade angle $\left({ }^{\circ}\right)$ & 24 & Inlet blade angle $\left({ }^{\circ}\right)$ & 25 \\
Outlet blade angle $\left({ }^{\circ}\right)$ & 26 & Outlet blade angle $\left({ }^{\circ}\right)$ & 90 \\
\hline
\end{tabular}

model pump are as follows: flow rate $(Q)$ is $120 \mathrm{~m}^{3} / \mathrm{h}$, head $(H)$ is $20 \mathrm{~m}$, speed $(n)$ is $1450 \mathrm{rpm}$, conveying particle volume concentration is from $5 \%$ to $15 \%$, and particle diameter is less than $20 \mathrm{~mm}$. Therefore, the specific speed [17]

$$
n_{s}=\frac{3.65 n \sqrt{Q}}{H^{3 / 4}}=102.17 \text {. }
$$

The main hydraulic component geometric parameters of the model pump are shown in Table 1.

As shown in Figure 4(a), the calculation domain of the flow field is composed of an inlet extension section, an impeller, a space guide vane, and an outlet extension section. The whole pump is placed vertically, and the inlet is at the bottom. The 3D model of the fluid domain is imported into ICEM CFD 18.0 software for grid division, and the grid diagram is demonstrated by Figure 4(b). DEM, as a meshless solver, needs to consume a lot of computing resources. And about $70 \%$ of the time in CFD-DEM coupling calculation is spent in DEM solution. If there are too many grid cells, a large amount of data exchange is needed between the CFD solver and DEM solver in each time step, which leads to low simulation efficiency. Meantime, too many grid cells mean that particles of the same size would occupy more grid cells, which would cause the EDM solver to be unstable. Thus, the grid cells used for simulation should not be too much, under the premise of accurate calculation. By irrelevance analysis, it is found that the variation of particle volume concentration will be within $5 \%$ when the mesh scale is around 50,000 . Finally, the total number of grid cells is 54,163 .

2.3. Simulation Parameter Settings. In this paper, pure water is selected as the continuous phase, particles are the discrete phase, and the volume concentration of particles at the model pump inlet is $5 \%$. The particles are set as spherical particles with three diameters of $5 \mathrm{~mm}, 10 \mathrm{~mm}$, and $15 \mathrm{~mm}$. 


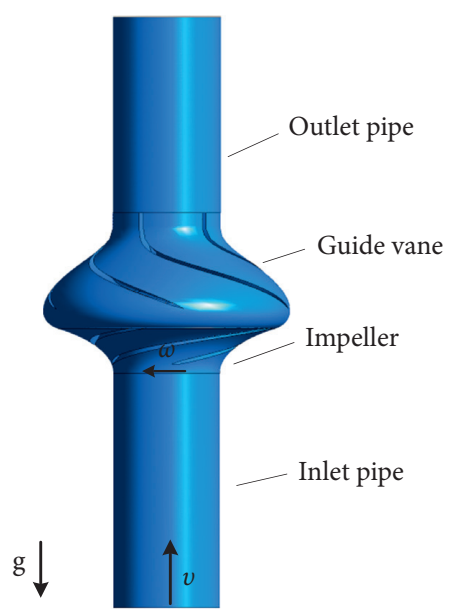

(a)



(b)

FIgUre 4: Model pump: (a) 3D model; (b) grid diagram.

The Hertz-Mindlin no-sliding model is used for the collision between particles and between particles and model pump. The pump body is made of aluminium alloy, its shear modulus is $70 \mathrm{MPa}$, and Poisson's ratio is 0.3 . And Particles are experimentally simulated particles, the shear modulus is 21.3 MPa, and Poisson's ratio is 0.4. Besides, the coefficients of static friction and rolling friction between particles are 0.27 and 0.01 , respectively, and those between particles and pump are 0.15 and 0.01 , respectively.

In this paper, the unsteady calculation of the model pump is carried out by Fluent 18.0 and EDEM 2018. The total simulated physical time is $5 \mathrm{~s}$, and the one simulation time step is set to $0.0001 \mathrm{~s}$, which is about the time step of $1^{\circ}$ impeller rotation. In the Fluent-EDEM coupling calculation, the particle calculation time step must not be greater than the fluid calculation time step. Refer to the Rayleigh time step, which is being controlled within $60 \%$, the time step for $5 \mathrm{~mm}$ particles working conditions is set to $0.00005 \mathrm{~s}$, and the time step for $10 \mathrm{~mm}$ and $15 \mathrm{~mm}$ particles is set to $0.0001 \mathrm{~s}$. The RNG $\kappa-\varepsilon$ model is used in the turbulence model. The impeller is set in the rotating coordinate system, and the guide vane is in the stationary coordinate system. The gravity acceleration is $9.81 \mathrm{~m} / \mathrm{s}^{2}$, and the gravity direction is opposite to the pump inlet direction. The velocity inlet is adopted as the inlet boundary, the flow at the inlet is assumed to be axisymmetric and no-prerotation, and the outflow boundary is adopted at the outlet boundary. The wall of the pump is set by no-slip boundary condition, and the standard wall function is used near the wall.

\section{CFD-DEM Numerical Simulation Results and Analysis}

The spatial distribution and movement characteristics of the particles in the slurry model pump had a great influence on the performance of the pump, including the patency of the flow and the abrasion of the impellers and guide vane. For a given flow channel, at the same particle volume concentration, the larger the particle diameter, the fewer the number of particles in the flow channel, and vice versa. Large particles mean that the kinetic energy required for their movement would also be greater. This paper used the CFD-DEM coupling model to analyse the movement characteristics of particles with different diameters (namely, $5 \mathrm{~mm}, 10 \mathrm{~mm}$, and $15 \mathrm{~mm}$ ), in which the density of different particle diameters is $2000 \mathrm{~kg} / \mathrm{m}^{3}$, and their effects on the flow field in the slurry pump.

\subsection{Spatial Distribution of Particles with Different Particle} Diameters. The particle volume concentration in the whole pump domain changes with the simulation time as shown in Figure 5. During the initial working period of the simulation, the volume concentration of the particle phase in the pump gradually increased. After running for a period, about $0.5 \mathrm{~s}$, the volume concentration does not continue to increase and stabilizes at about $5 \%$. So, combined with the feature of the residual error of numerical computation convergence, the simulation is considered to be stable. As shown in Figure 5, the actual particle volume concentration under all different particle diameters shows some fluctuations, and the fluctuation range is violent with the increase of particle diameter. From this figure, it also shows that the average particle volume concentration in the pump increases with the increase of particle diameters. When the particle diameter is $15 \mathrm{~mm}$, the average particle volume concentration in the pump will be around $5.5 \%$.

The average particle volume concentrations with different particle diameters are obtained by analysing the simulation results in a relatively stable period, from $1 \mathrm{~s}$ to $5 \mathrm{~s}$, as shown in Table 2. With the increase of particle diameter, the volume concentration of particles also gradually increases. However, they are all higher than the volume concentration at the inlet $(5 \%)$, which indicated that particles had local aggregation in the pump, and with the increase of particle diameter, the aggregation is more obvious. However, although the aggregation phenomenon occurs, the concentration of each part of the pump in the stable state is constant, indicating that there is no blockage in the flow channel of the pump. Figure 6 shows the relative volume concentration of particles in each part of the pump. 


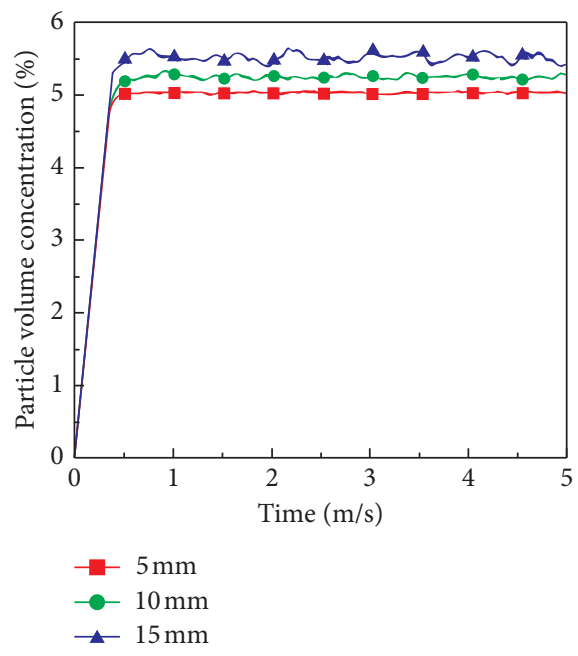

FIGURE 5: Particle volume concentration pulsation curve of various sizes.

TABLE 2: Particle volume concentration at a stable moment.

\begin{tabular}{lccc}
\hline Particle diameter $(\mathrm{mm})$ & Particle volume $\left(\mathrm{m}^{3}\right)$ & Flow channel volume $\left(\mathrm{m}^{3}\right)$ & Volume concentration $(\%)$ \\
\hline 5 & $5.95 \times 10^{-4}$ & $1.18 \times 10^{-2}$ & 5.04 \\
10 & $6.21 \times 10^{-4}$ & $1.18 \times 10^{-2}$ & 5.25 \\
15 & $6.53 \times 10^{-4}$ & $1.18 \times 10^{-2}$ & 5.53 \\
\hline
\end{tabular}

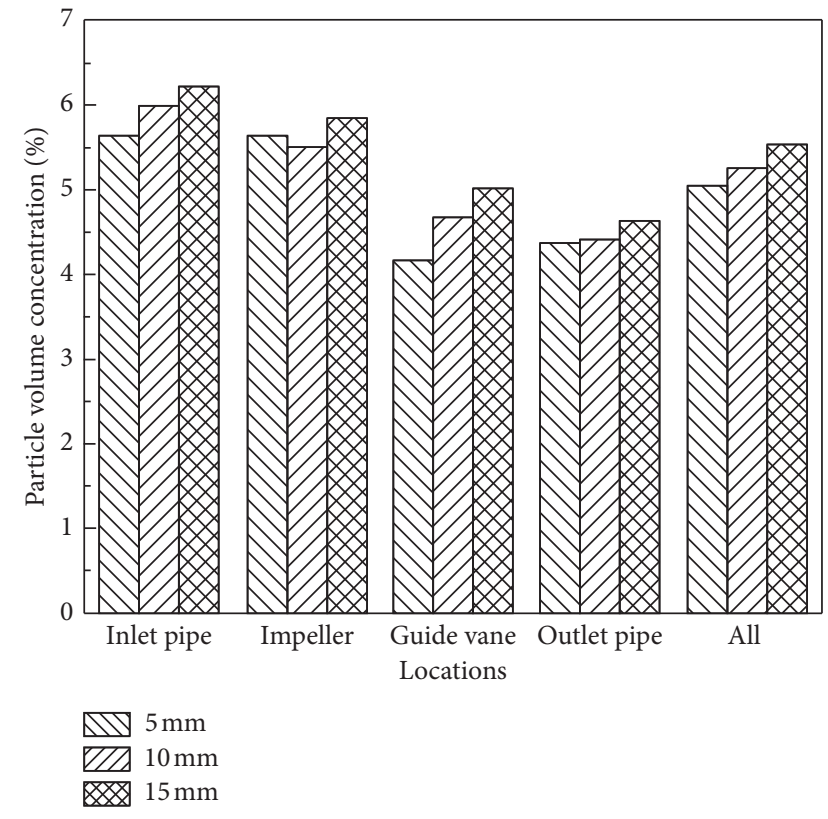

Figure 6: Particle volume concentration at various flow components.

The spatial distribution of particles in each part of the pump is shown in Figure 7. In the inlet of the pump, the particles and water are injected at the same velocity. Due to the action of gravity, particle sedimentation phenomenon will happen. And the larger the particles, the more obvious the settlement phenomenon [18]. According to particle velocity statistics, the average vertical velocity of particles of
$5 \mathrm{~mm}, 10 \mathrm{~mm}$, and $15 \mathrm{~mm}$ is $2.07 \mathrm{~m} / \mathrm{s}, 1.97 \mathrm{~m} / \mathrm{s}$, and $1.89 \mathrm{~m} /$ $\mathrm{s}$, respectively, which are all lower than the $2.33 \mathrm{~m} / \mathrm{s}$, which is the water velocity in the inlet of the impeller section.

However, after the particles are accelerated by the impeller, they entered the outlet pipe at a higher velocity from the guide vanes. Under the "damping" actions of gravity and water, the velocity of particles of all diameters would gradually decrease. The velocity of the particles in the outlet of the pump drops to $3.22 \mathrm{~m} / \mathrm{s}, 3.12 \mathrm{~m} / \mathrm{s}$, and $3.05 \mathrm{~m} / \mathrm{s}$, respectively, but it is still higher than the velocity of the water in the same section, about $2.89 \mathrm{~m} / \mathrm{s}$.

3.2. Movement Characteristics of Particles with Different Particle Diameters. Figure 8 shows the distribution of particles in the impeller, and there are two significant features. The first feature is the accumulation of low-speed particles at the entrance of the impeller. When particles enter the impeller at a lower speed, the first entering particles collided with the blades and shroud and rebound to collided again with the particles that entering the impeller later. As the number of particles increases in this section, the collision probability gradually raises. So, kinetic energy is quickly dissipated with the collision, and the velocity of the particle is further reduced, forming a particle aggregation phenomenon at the entrance of the impeller. Secondly, the small particles moved close to the pressure surface of the blades in the middle of the flow channel, while the large particles are relatively evenly distributed. This is because low-speed particles get some kinetic energy from high-speed rotating blades, and small particles have smaller inertia, better water-following ability, and easier to 


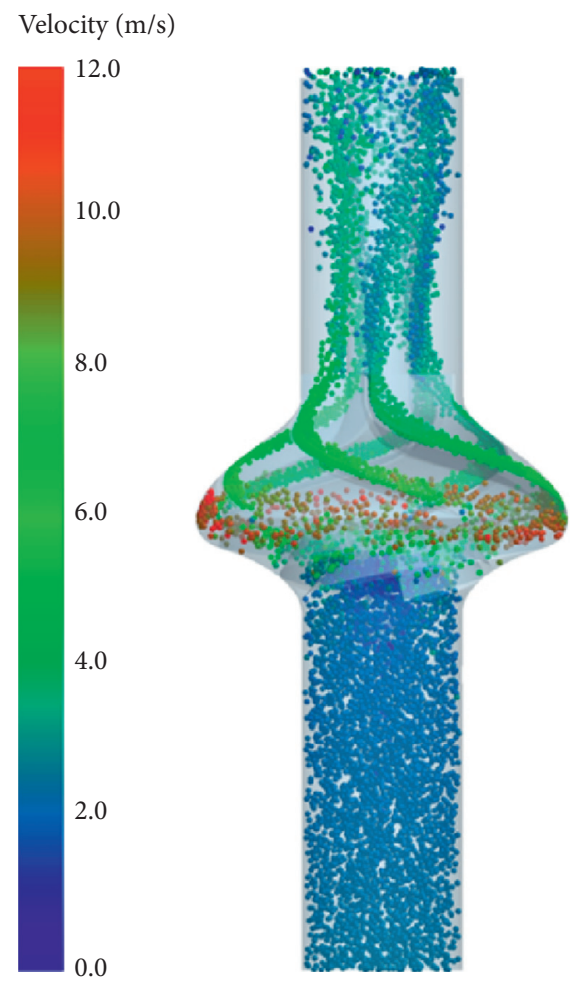

(a)

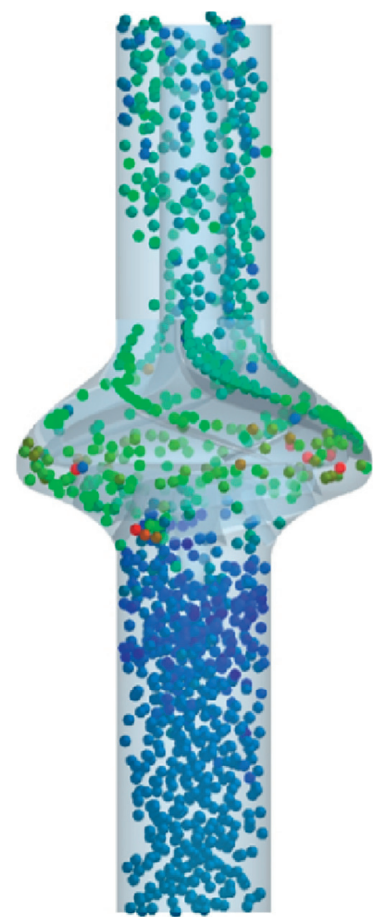

(b)

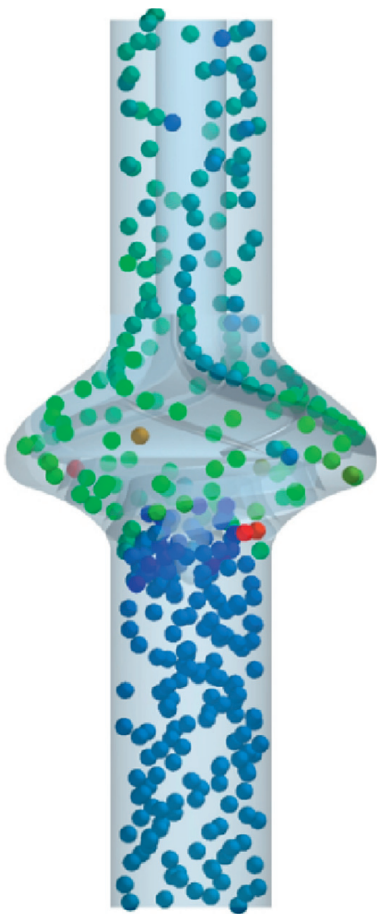

(c)

Figure 7: Particle volume distribution of the whole flow domain: (a) $5 \mathrm{~mm}$, (b) $10 \mathrm{~mm}$, and (c) $15 \mathrm{~mm}$.

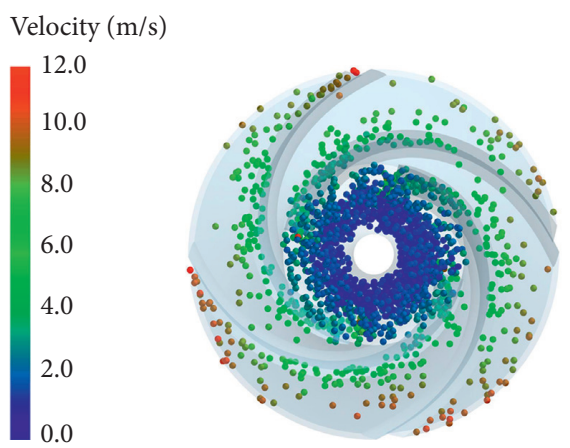

(a)

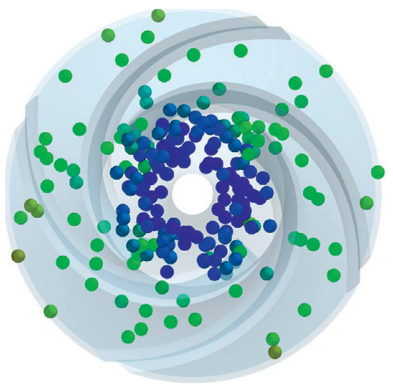

(b)

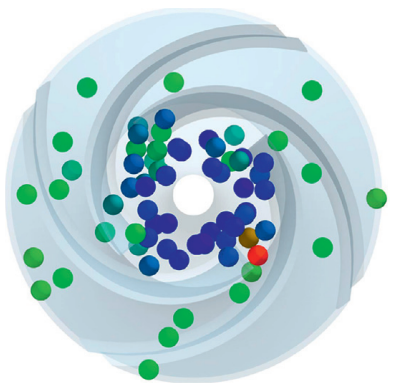

(c)

Figure 8: Particle distribution in impeller region: (a) $5 \mathrm{~mm}$, (b) $10 \mathrm{~mm}$, and (c) $15 \mathrm{~mm}$.

move close to the pressure surface of the blades than large particles.

According to statistics, the average velocity of $5 \mathrm{~mm}$, $10 \mathrm{~mm}$, and $15 \mathrm{~mm}$ particles at the entrance of the guide vane channel is $9.59 \mathrm{~m} / \mathrm{s}, 8.49 \mathrm{~m} / \mathrm{s}$, and $8.53 \mathrm{~m} / \mathrm{s}$, respectively. The difference in the average velocity of particles of different diameters reflected, to some extent, the ability of particles of different diameters to obtain energy from the impeller. Figure 9 shows the distribution of particles in the guide vane. After the particles enter the guide vane channel, due to particles' inertia, they continue to maintain the original motion trend, and then the particles will collide with the pressure surface of the stationary guide vane. Under the hindrance of the pressure surface, the direction of motion of the particles becomes along the pressure surface. Due to the collision and friction between the particles and the wall of the guide vane, the particle velocity gradually decreases. Besides, it can be seen from Figure 9 that small particles present the characteristic of multilayer continuous slips, while large particles are mostly single-layer or discrete slips.

\subsection{The Influence of Different Particle Diameters on the Stress Distribution}

3.3.1. The Influence of Different Particle Diameters for Stress Distribution of the Impeller. The pressure distribution on the pressure surface of blades with different particle diameters is shown in Figure 10. On the whole, under different particle diameters, the pressure distribution difference on the 




(a)

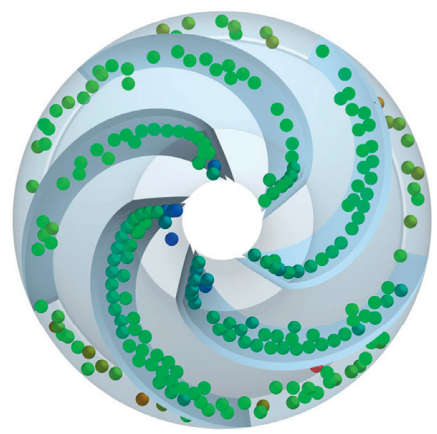

(b)

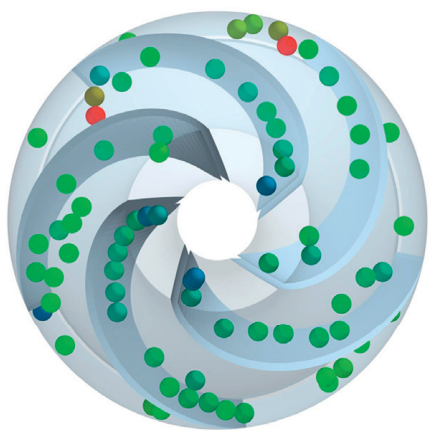

(c)

Figure 9: Particle distribution in guide vane region: (a) $5 \mathrm{~mm}$, (b) $10 \mathrm{~mm}$, and (c) $15 \mathrm{~mm}$.

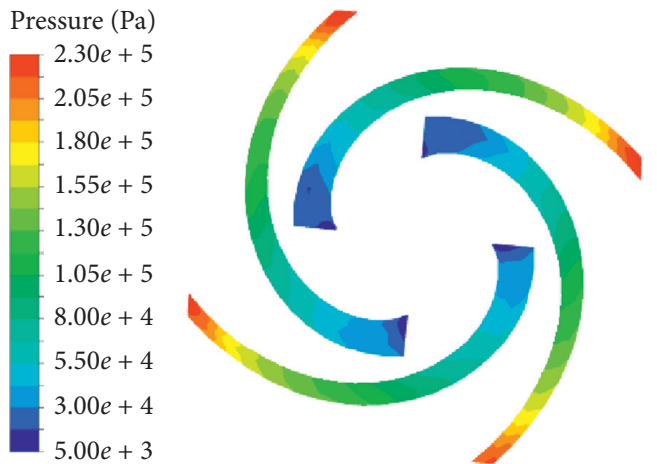

(a)

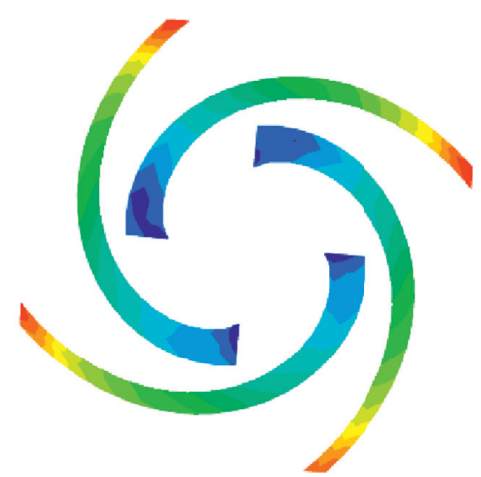

(b)

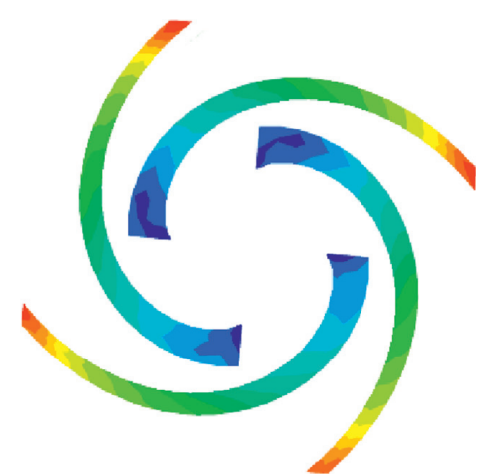

(c)

FIgURE 10: Pressure distribution on the pressure surface of the impeller: (a) $5 \mathrm{~mm}$, (b) $10 \mathrm{~mm}$, and (c) $15 \mathrm{~mm}$.

pressure surface is small, and the pressure trend of all particle diameter conditions is keeping increasing from inlet to outlet of the impeller. As shown in Figure 10(a), under the working condition of small particle diameter $(d=5 \mathrm{~mm})$, the low-pressure areas of the blades pressure surface are very small and only appeared at the inlet of the impeller; as the particle diameter increased, the low-pressure areas in the pressure surface of the impeller inlet gradually increase and expand toward the impeller outlet, as shown in Figures 10(b) and $10(\mathrm{c})$.

Figure 11 shows the pressure distribution on the suction surface of the blades under different particle diameter conditions. The overall pressure trend is the same as that of the blade pressure surfaces, and both show an increasing trend from the impeller inlet to the outlet. However, with the particle diameter increases, the low-pressure areas at the inlet of the suction surface decreased significantly.

It can be seen from Figure 12 that the pressure of the impeller blades increased with various particle diameters; however, by comparing the pressure curves under different particle diameters, it is not difficult to find that the blade pressure with $5 \mathrm{~mm}$ particle diameter is significantly greater than that of large particles $(d \geq 10 \mathrm{~mm})$. When the particle diameter, $d$, is $5 \mathrm{~mm}, 10 \mathrm{~mm}$, and $15 \mathrm{~mm}$, the average pressure on the pressure side is $106387 \mathrm{~Pa}$,
$102791 \mathrm{~Pa}$, and $102242 \mathrm{~Pa}$; the average pressure on the suction side is $32913 \mathrm{~Pa}, 31447 \mathrm{~Pa}$, and $30943 \mathrm{~Pa}$. Differently, for the negative pressure area on the suction surface of the blades, as the particle diameter increases, the negative pressure value rises slightly.

\subsubsection{The Influence of Different Particle Diameters for Stress} Distribution of the Guide Vane. Under different particle size working conditions, the pressure changes in the guide vane are shown in Figure 13. At the entrance of the guide vane, the high-pressure area decreases significantly with the increase of particle diameters from $5 \mathrm{~mm}$ to $15 \mathrm{~mm}$. This is because the small particles $(d=5 \mathrm{~mm})$ are distributed in multilayer and continuous distribution in the guide vane (shown in Figure 9), and the impact area on the guide vane blade is larger, while the large particles $(d=10 \mathrm{~mm}$ and $15 \mathrm{~mm}$ ) form a single layer in the guide vane, so the impact on the inlet pressure surface of guide vane is more concentrated. From the middle of the pressure surface of the guide vane to the outlet, the overall pressure also shows a downward trend with the increase of particle diameter, but when the particle diameter is $5 \mathrm{~mm}$, the pressure distribution is relatively uniform, while under the condition of large particle diameter, the low-pressure area increased obviously. This is 


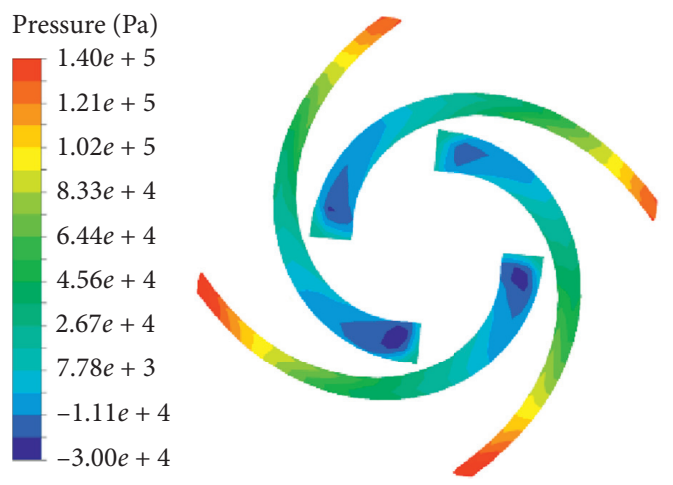

(a)

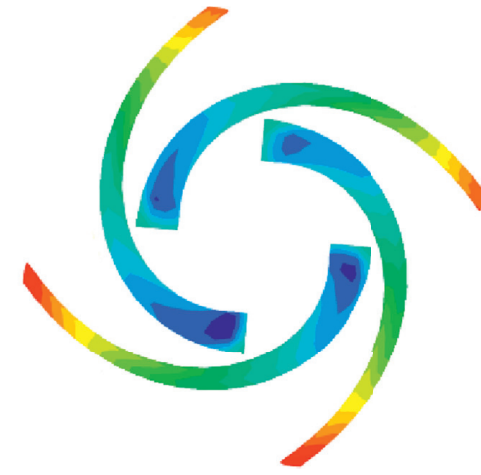

(b)

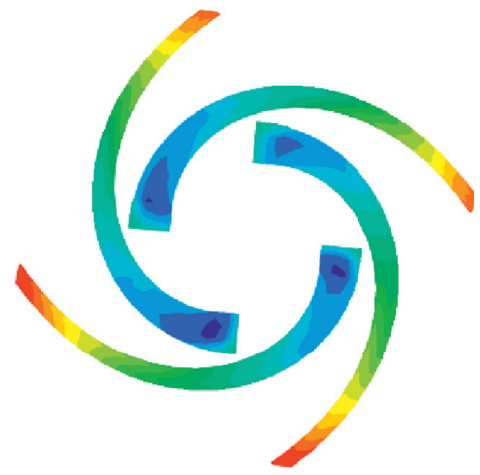

(c)

Figure 11: Pressure distribution on the suction surface of the impeller: (a) $5 \mathrm{~mm}$, (b) $10 \mathrm{~mm}$, and (c) $15 \mathrm{~mm}$.

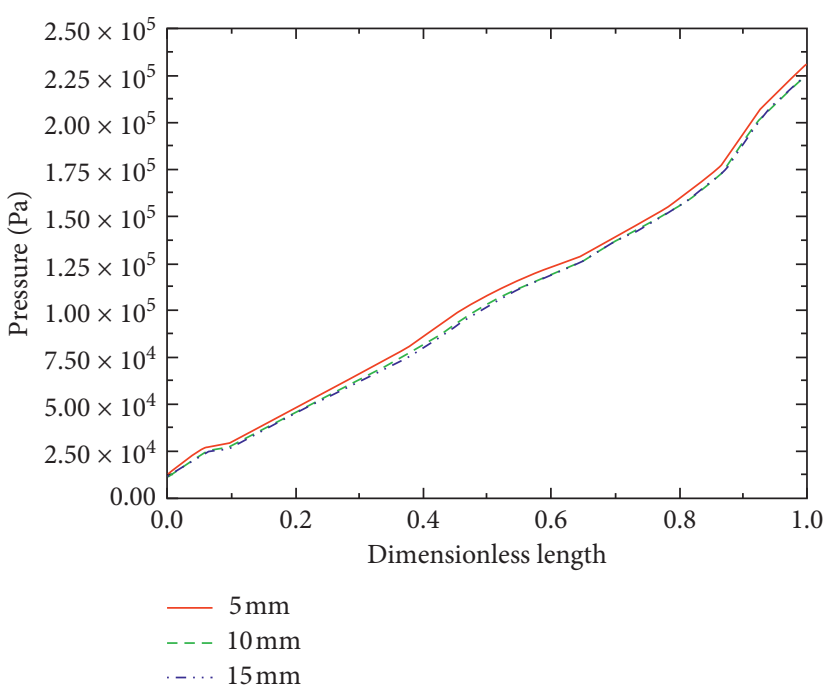

(a)

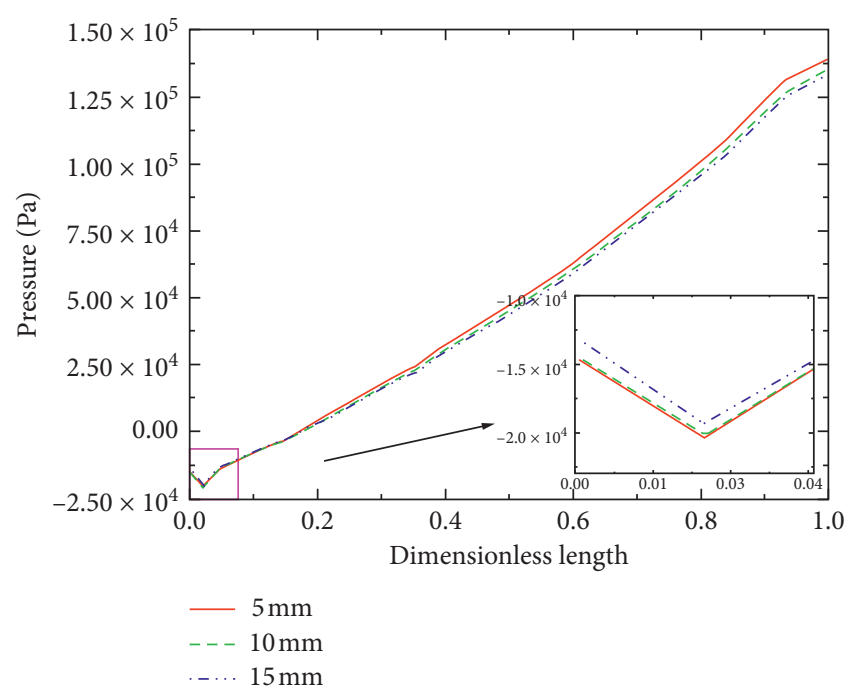

(b)

FIGURE 12: Pressure distribution of the impeller: (a) pressure surface and (b) suction surface.

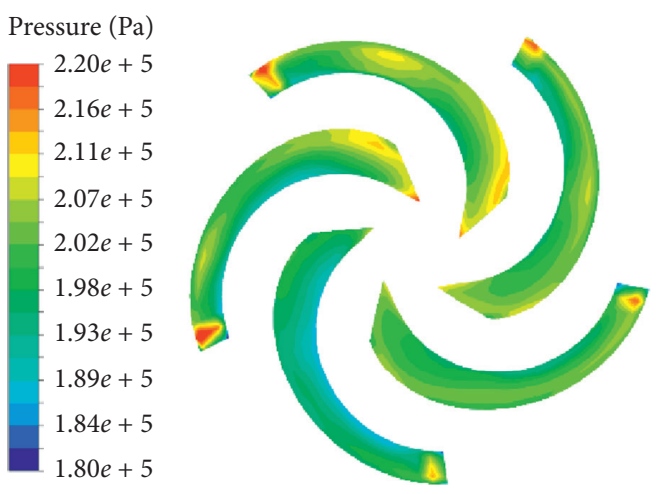

(a)



(b)



(c)

FIgURe 13: Pressure distribution on the pressure surface of the guide vane: (a) $5 \mathrm{~mm}$, (b) $10 \mathrm{~mm}$, and (c) $15 \mathrm{~mm}$.

due to the large space occupied by small particles in the guide vane. Thus, it, to some extent, suppresses the generation of low-pressure zones. As shown in Figure 14, the suction surface pressure of the guide vane also decreases following the increase of the particle diameter, and the area of the low-pressure zone has increased, but it is not obvious. 


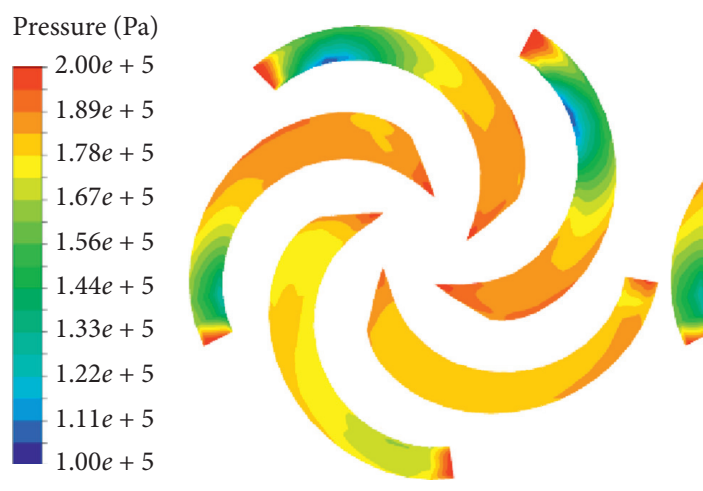

(a)



(b)

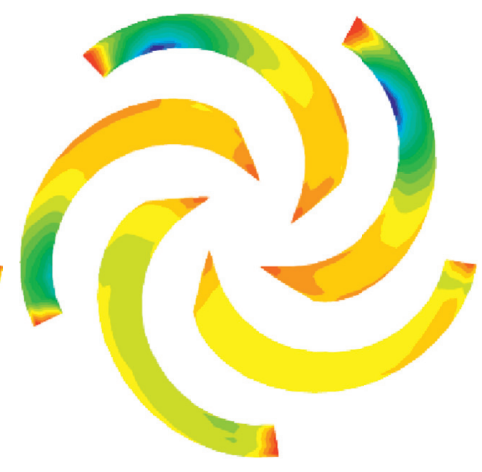

(c)

Figure 14: Pressure distribution on the suction surface of the guide vane: (a) $5 \mathrm{~mm}$, (b) $10 \mathrm{~mm}$, and (c) $15 \mathrm{~mm}$.

Figure 15 shows the pressure distribution of the pressure surface and the suction surface from the guide vane inlet to the outlet of the guide vane, which shows an overall growth trend, where the left is the pressure distribution curves of the pressure surface and the right is the pressure distribution curves of the suction surface. When the particle diameter, $d$, is $5 \mathrm{~mm}, 10 \mathrm{~mm}$, and $15 \mathrm{~mm}$, the average pressure on the pressure surface is $200810 \mathrm{~Pa}, 197022 \mathrm{~Pa}$, and $195851 \mathrm{~Pa}$, and the average pressure on the suction surface is $180001 \mathrm{~Pa}$, $176506 \mathrm{~Pa}$, and $175272 \mathrm{~Pa}$. It is not difficult to see that, following the particle diameter increases, both the pressure side and the suction side have a downward trend concerning pressure.

\subsection{The Influence of Different Particle Diameters on the Velocity Distribution}

3.4.1. The Influence of Different Particle Diameters for Velocity Distribution of the Impeller. Figure 16 shows the velocity change curves in the impeller flow channel under different particle sizes. The fluid velocity with different particle diameters in the impeller shows a similar trend. As shown in Figure 16(a), under different particle diameter conditions, the outlet velocity had a certain increase compared to the inlet, but there are two obvious inflection points along with the blades. Before the first inflection point, the fluid just entered the impeller, and its speed slowly increases under the drive of the impeller; when the fluid reached the entrance of the blade, due to the squeezing effect of the blade on the particles, the spatial distribution of particles changed from uniform state in the inlet pipe to the distribution by flow paths of the impeller. The changes in particle distribution shape have an obstructive effect on the fluid, to a certain extent, resulting in a decrease in water velocity. At the same time, due to the gradual increase in the flow area of the impeller, also led to a decreasing tendency in the fluid velocity, thus produces the first inflection point $(L=0.25)$. After some time, the flow pattern of particles and fluid tends to be stable. The velocity of the fluid gradually increases when particles and fluid get enough energy from the impeller blades. So, particles are not known as the main obstacle to increasing fluid velocity. Therefore, the second inflection point $(L=0.65)$ appears. After that, the velocity of the fluid increases gradually under the influence of impeller rotation and reaches the highest speed near the outlet of the impeller. By comparing the speed changes with different particle diameters, it is not difficult to find that $L=0.75$ is a very critical position. Before $L=0.75$, the relative velocity of the fluid with small particles $(d=5 \mathrm{~mm})$ is significantly greater than that under large particle conditions $(d=10 \mathrm{~mm}$ and $15 \mathrm{~mm}$ ). After $L=0.75$, the larger the particle diameter, the greater the relative velocity in the impeller flow channel. And the higher relative velocity of outlet fluid represents that less energy is obtained by particles, so Figure 16(a) can reflect that the ability of small particles to obtain energy from the fluid is better than that of large particles.

Figure 16(b) shows the lines of the average relative velocity between the front shroud and the rear shroud of the impeller with three different particle diameters. Since the particles are mostly concentrated near the front shroud, the fluid is being squeezed by the particles, so the relative velocity near the front shroud is significantly higher than that near the rear shroud. Nevertheless, although the particle diameter changes greatly from $5 \mathrm{~mm}$ to $15 \mathrm{~mm}$, the particle volume fraction is the same. Therefore, under different particle diameter conditions, the velocity difference is relatively small, especially in large particle diameters, $d=10 \mathrm{~mm}$ and $15 \mathrm{~mm}$, and the relative speed curves almost overlap.

3.4.2. The Influence of Different Particle Diameters for Velocity Distribution of the Guide Vane. Figure 17 shows the streamline diagram of the flow field in the guide vane. The fluid velocity is generally decreasing, and there are obvious vortices in the guide vane channel, ranging from the inlet of the guide vane to the middle part of it. And there are different flow characteristics in different channels. By comparing the streamline diagram, it can be seen that the streamline distribution and the location of the vortex are relatively consistent. However, as the particle diameter increases, the streamlines of the vortex became denser and the vortex become stronger.

Figure 18 shows the velocity distribution of fluid in the guide vane. As shown in Figure 18(a), the velocity from the 


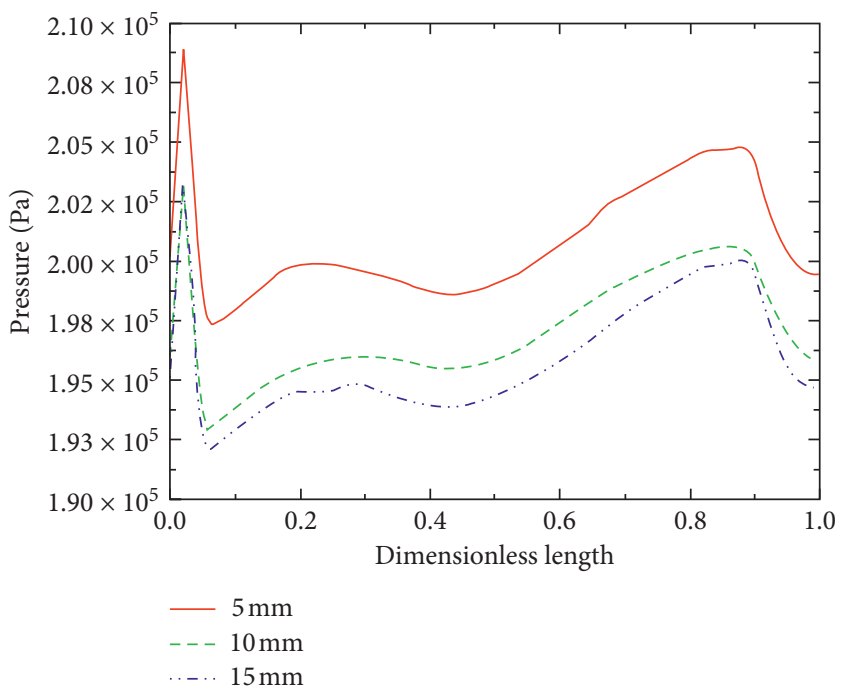

(a)

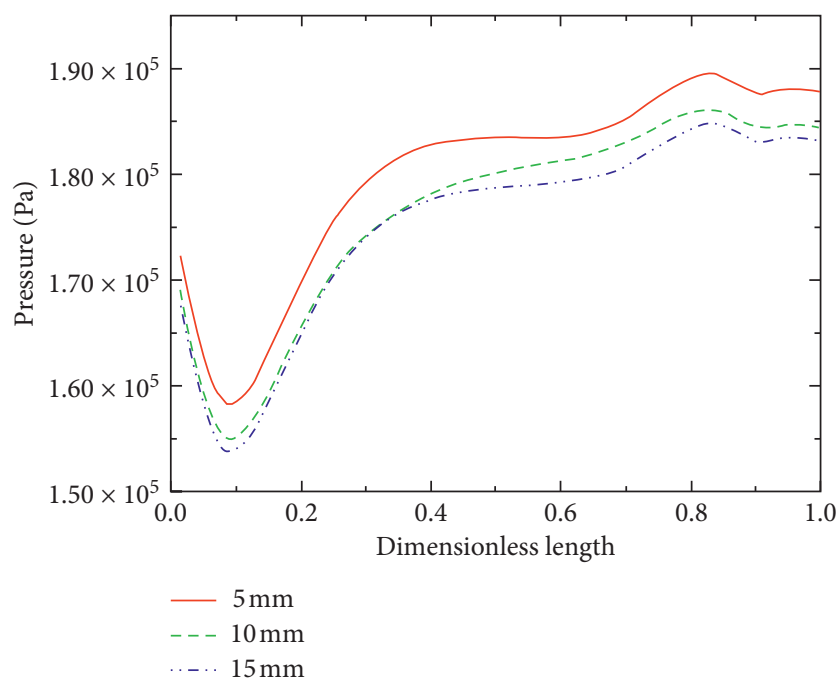

(b)

FIgURE 15: Pressure distribution curves of the guide vane: (a) pressure surface and (b) suction surface.

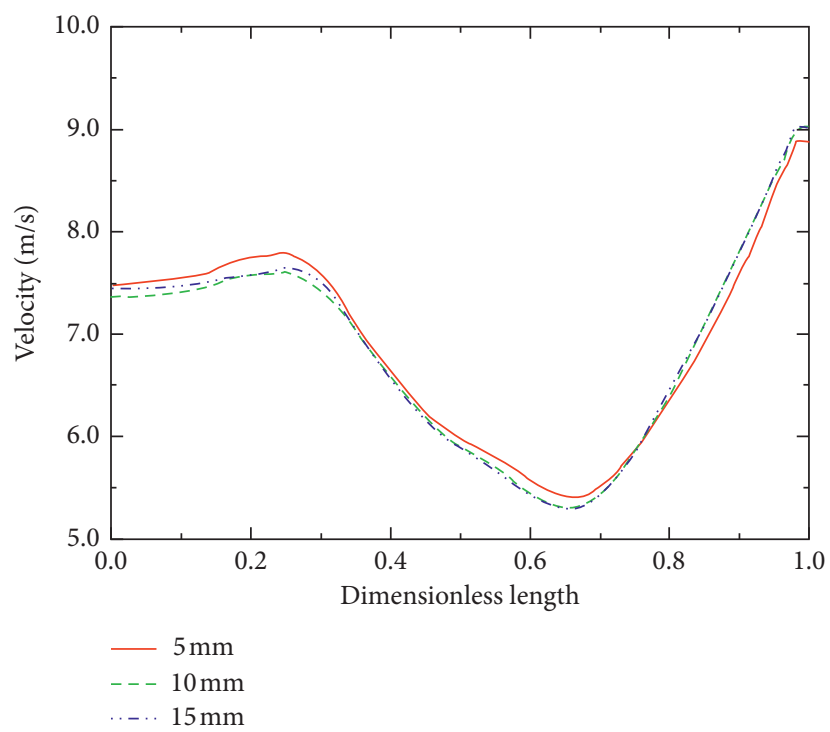

(a)

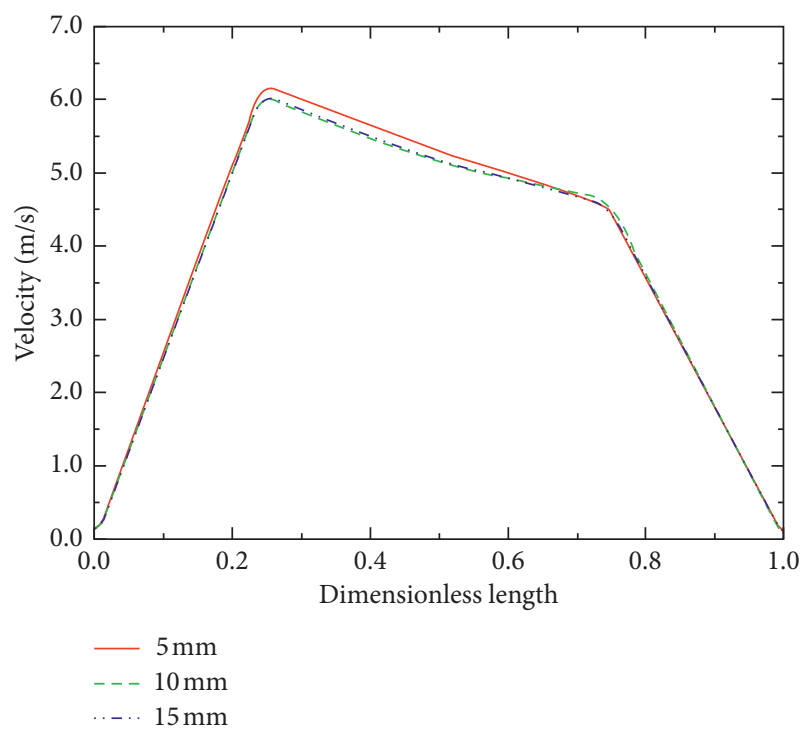

(b)

FIGURE 16: Relative velocity curves in the impeller: (a) from the inlet to the outlet and (b) from the front shroud to the rear shroud.

inlet to the outlet of the guide vane has a decreased tendency, and there is no significant difference in velocity with different particle diameters. Besides, because of the existence of the vortex in the middle of the guide vane (seen in Figure 17), the average velocity of this region is affected, so the velocity curve showed a concave tendency. After the vortex effect is over, the average velocity has an obvious increase. Figure 18(b) shows the velocity curves from the front shroud to the rear shroud of the guide vane. In the case of large particle diameter $(d=10 \mathrm{~mm}$ and $15 \mathrm{~mm}$ ), the velocity has an obvious peak near $L=0.2$, while for small particles, the speed change is relatively smooth. This is due to the accumulation of lots of small particles in this area, which prevents the rapid change of fluid velocity.

\section{Experimental Verification}

In order to verify the accuracy of numerical simulation, a slurry model pump test system as shown in Figure 19 was built, which consists of a slurry model pump, water tanks, a particle tank, a feeding particle machine, a calibration box, circulation pipeline, some testing device, etc. During the test, the pump outlet pressure is controlled by adjusting the valve to obtain the characteristics of the model pump. The test system includes sensors such as pressure sensors at the inlet 


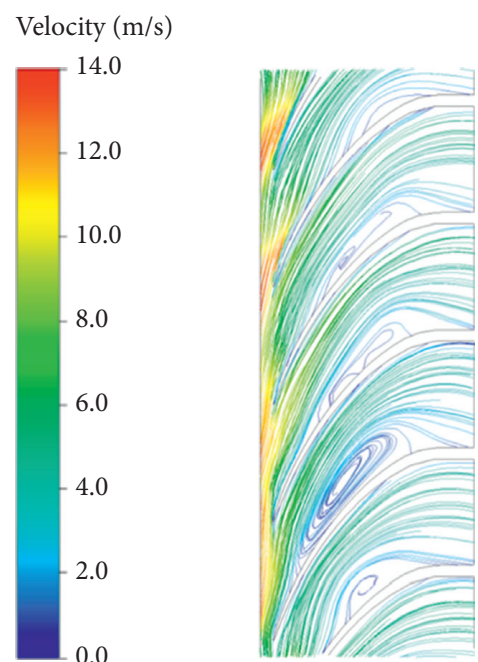

(a)

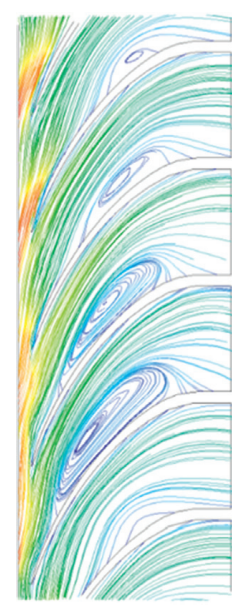

(b)

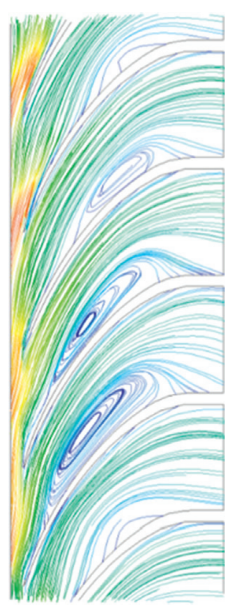

(c)

Figure 17: Streamline diagram of the guide vane: (a) $5 \mathrm{~mm}$, (b) $10 \mathrm{~mm}$, and (c) $15 \mathrm{~mm}$.

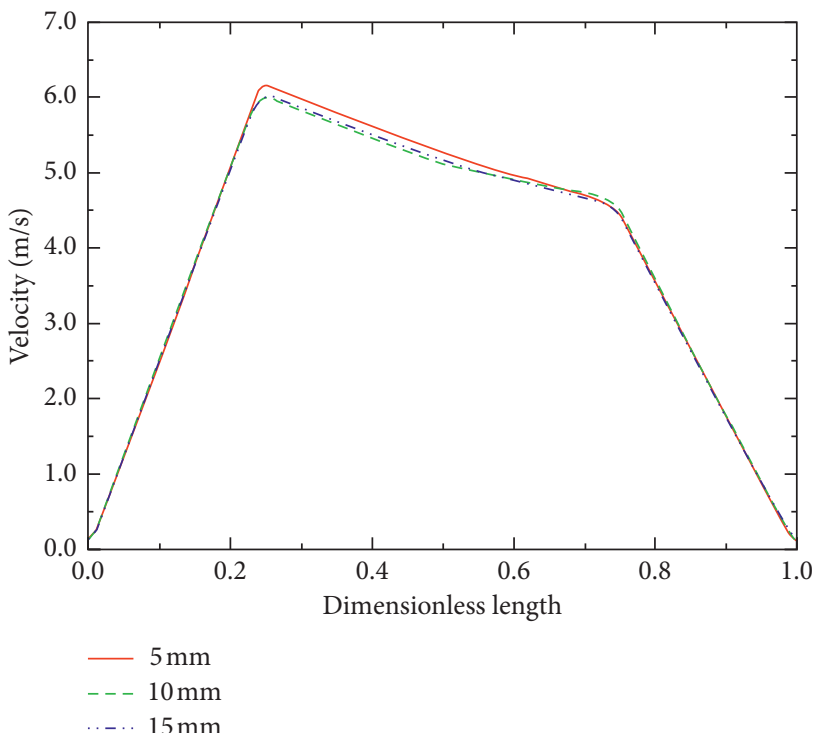

(a)

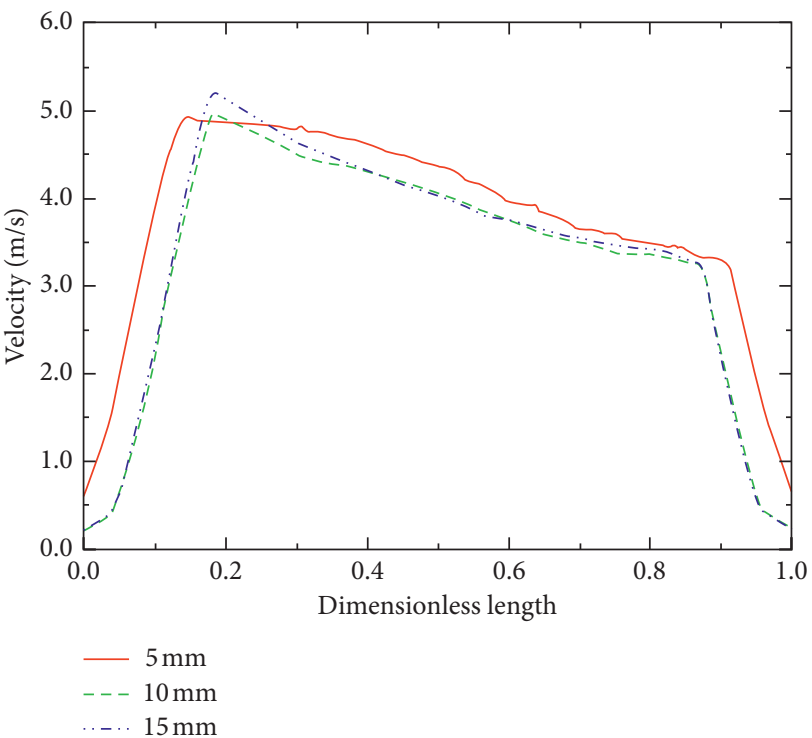

(b)

Figure 18: Velocity curves in the guide vane: (a) from the inlet to the outlet and (b) from the front shroud to the rear shroud.

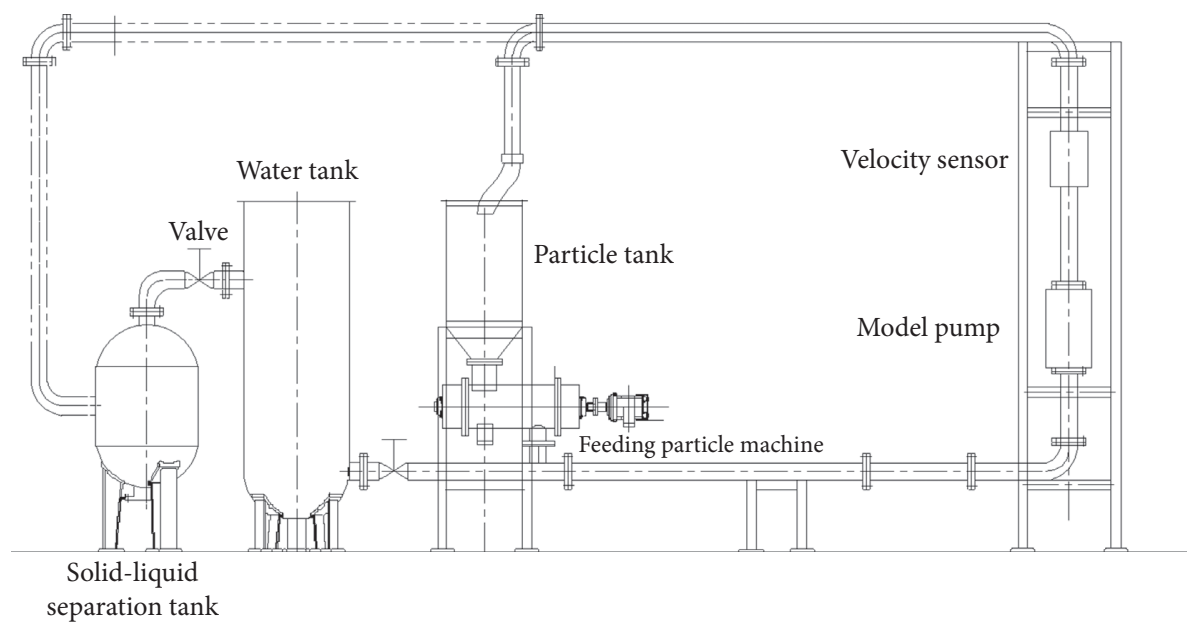

Figure 19: Schematic diagram of the slurry model pump test system. 


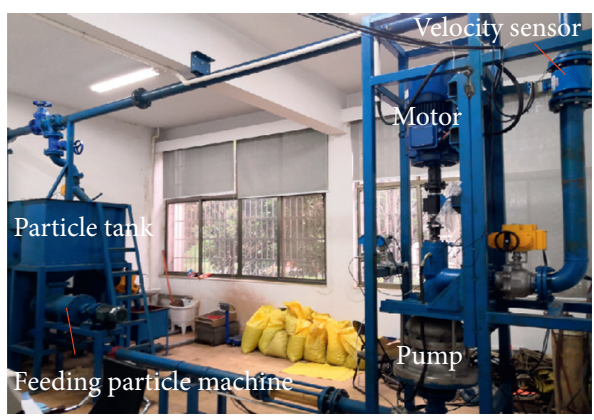

(a)

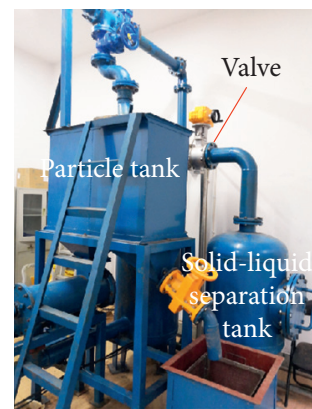

(b)

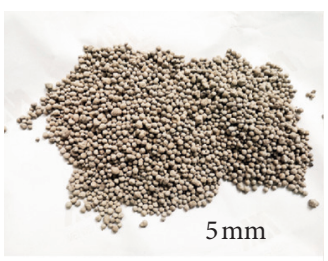

(c)

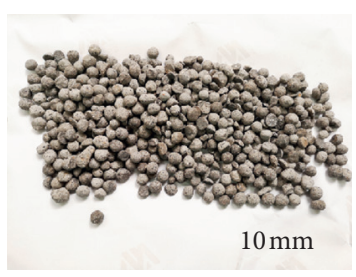

(d)

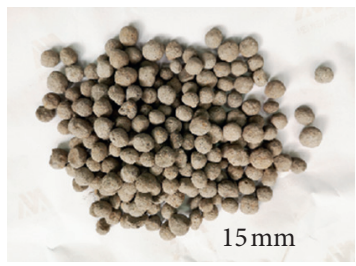

(e)

Figure 20: The experiment system and particles: (a) overall view of the test system, (b) side of the test system, (c) $5 \mathrm{~mm}$ particles, (d) $10 \mathrm{~mm}$ particles, and (e) $15 \mathrm{~mm}$ particles.

TABle 3: Comparison of calculation and experiment.

\begin{tabular}{lcccccc}
\hline $\begin{array}{l}\text { Particle diameter } \\
(\mathrm{mm})\end{array}$ & $\begin{array}{c}\text { Simulation head } \\
(\mathrm{m})\end{array}$ & $\begin{array}{c}\text { Test head } \\
(\mathrm{m})\end{array}$ & $\begin{array}{c}\text { Simulation } \\
\text { efficiency }(\%)\end{array}$ & $\begin{array}{c}\text { Test efficiency } \\
(\%)\end{array}$ & $\begin{array}{c}\text { Relative error of } \\
\text { head }(\%)\end{array}$ & $\begin{array}{c}\text { Relative error of } \\
\text { efficiency }(\%)\end{array}$ \\
\hline 5 & 19.15 & 18.99 & 68.70 & 71.02 & 0.84 & 3.27 \\
10 & 18.91 & 18.84 & 67.78 & 70.46 & 0.37 & 3.80 \\
15 & 18.69 & 18.76 & 67.08 & 70.14 & 0.37 & 4.36 \\
\hline
\end{tabular}

and outlet of the pump, flow velocity sensors, rotational speed, torque sensors, and signal acquisition and data processing systems. All the sensor errors are within 3\% to ensure the accuracy of the test data. Figure 20 shows photos of the test system and particles with three different diameters.

The comparative data of the model pump head and efficiency between numerical simulation and experiment are shown in Table 3. The relative errors of numerical simulation of head and efficiency are within 5\%, which indicates that the numerical simulation results are accurate. The head and efficiency decrease with the increase of particle diameter, which is related to the hydraulic loss caused by the velocity difference between water and particles. And the larger the particle diameter, the greater the energy loss, resulting in the decrease of pump head and efficiency.

\section{Conclusions}

In this paper, the numerical and experimental study of the slurry model pump in a deep-sea mining system is carried out. The motion characteristics of particles in the slurry model pump and the influence of the solid phase on the fluid field are analysed. The following conclusions are obtained by simulation and test.
(1) The CFD-DEM coupling model based on the Euler-Lagrangian method can accurately calculate the complex flow of large particle solid-liquid twophase flow in a slurry pump.

(2) The local accumulation effect of particles in the pump is produced. The particle volume concentration in the impeller and guide vane is higher than in the pipeline. And the larger the particle diameter, the higher the local volume concentration in the model pump. Particles and fluids show obvious stratified motion in the impeller and guide vane.

(3) The existence of particles leads to flow separation. The diffusion of the flow area and the internal loss of the solid-liquid phase are the main causes of energy loss in the model pump. With the increase of particle diameter, the pressure distribution and velocity in the model pump become more uneven, and the performance of the pump shows a downward trend.

(4) Through the comparison of the above, the flow field about the slurry model pump with small particles is more stable and less energy dissipation. And the ability of small particles to gain energy is better than that of the larger particles. In the future, the particle diameter should not be too large for offshore testing. 


\section{Data Availability}

The data used to support the findings of this study are included within the article.

\section{Conflicts of Interest}

The authors declare that they have no conflicts of interest.

\section{Acknowledgments}

This work was supported by the NSFC program, nos. 51706206 and 51976197, Zhejiang Public Welfare Projects, no. LGF19E060001, Starting Foundation of Zhejiang Sci-Tech University, no. 16022180-Y, and Postdoctoral Sustentation Fund, no. 2017M622561.

\section{References}

[1] W. S. Zou and J. Z. Huang, "Lifting technology for mining deep-sea manganese nodule," Mining and Metallurgical Engineering, vol. 26, no. 3, pp. 1-5, 2006.

[2] Y. X. Xiao, L. B. Yang Lingbo, L. Cao, and Z. W. Wang, "Distribution of marine mineral resource and advances of deep-sea lifting pump technology," Journal of Drainage and Irrigation Machinery Engineering, vol. 32, no. 4, pp. 319-326, 2014.

[3] S. Liu, N. Yang, and Q. Han, "Research and development of deep sea mining technology in China," in Proceedings of the ASME 2010 29th International Conference on Ocean, Offshore and Arctic Engineering, pp. 163-169, American Society of Mechanical Engineers (ASME), Shanghai, China, 2010.

[4] G. Kuntz, "The technical advantages of submersible motor pumps in deep sea technology and the delivery of manganese nodules," in Proceedings of the Offshore Technology Conference, pp. 85-91, Houston, TX, USA, May 1979.

[5] TRAM, TRAM R\&D of Manganese Nodule Mining Systems, Japan Slurry Transport Association, Tokyo, Japan, 1991.

[6] P. A. Cundall and R. D. Hart, Development of Generalized 2-D and 3-D Distinct Element Programs for Modeling Jointed Rock, ITASCA Consulting Group, Inc., Minneapolis, MN, USA, 1985.

[7] P. A. Cundall and O. L. Strack, The Distinct Element Method as a Tool for Research in Granular Media, Part2, Report to the National Science Foundation, University of Minnesota, Minneapolis, MN, USA, 1979.

[8] W. Zou, "COMRA'S research on lifting motor pump," in Proceedings of the Seventh ISOPE Ocean Miming Symposium International Society of Offshore and Polar Engineers, pp. 177-180, Lisbon, Portugal, July 2007.

[9] W. S. Zou, A. L. Chen, and ZH. H. Li, "China's research on ylefling motor pump for deep sea ming," in Proceedings of the 13h International Conference on Transport \& Sedimentation of Solid Particles, Wroclaw, Poland, 2011.

[10] Y. C. Zeng, H. L. Xu, B. Wu, and Q. Chen, "Analysis on the influence of particle volume fraction on the lift pump work performance for deep-sea mining," Marine Science Bulletin, vol. 26, no. 1, pp. 67-73, 2017.

[11] H. L. Xu, Y. C. Zeng, Q. Chen, and B. Wu, "Numerical simulation of particle flow trajectory in slurry pump for deepsea mining," Journal of Central South University (Science and Technology), vol. 48, no. 1, pp. 84-90, 2017.
[12] S. Huang, X. Su, and G. Qiu, "Transient numerical simulation for solid-liquid flow in a centrifugal pump by DEM-CFD coupling," Engineering Applications of Computational Fluid Mechanics, vol. 9, no. 1, pp. 411-418, 2015.

[13] S. J. Liu, Y. W. Li, and X. Z. Hu, "Effect of particle volume fraction on the performance of deep-sea mining electric lifting pump base on DEM-CFD," Journal of Mechanical Engineering, vol. 56, no. 10, pp. 257-264, 2020.

[14] X. F. Gao, W. D. Shi, Y. Shi, H. Chang, and T. Zhao, "DEMCFD simulation and experiments on the flow characteristics of particles in vortex pumps," Water, vol. 12, Article ID 2444, 17 pages, 2020.

[15] Y.-w. Li, S.-j. Liu, and X.-z. Hu, "Research on rotating speed's influence on performance of deep-sea lifting motor pump based on DEM-CFD," Marine Georesources \& Geotechnology, vol. 37, no. 8, pp. 979-988, 2019.

[16] Y. W. Li, S. H. J. Liu, and X. Z. H. Hu, "Research on reflux in deep-sea mining pump based on DEM-CFD," Marine Georesources \& Geotechnology, vol. 38, no. 6, pp. 744-752, 2020.

[17] B. L. Cui, Z. Wan, Z. C. Zhu, and Y. G. Lin, "Research on optimum design of low-specific-speed complex impeller centrifugal pump based on 3-dimensional flow analysis," in Proceedings of the 7th International Conference on Fluid Power Transmission and Control, pp. 792-797, Hangzhou, China, April 2009.

[18] G. G. Chen, N. Yang, D. S. Tang et al., "Study on the settling regularity of solid particles in vertical pipelines," Journal of Sediment Research, vol. 4, pp. 16-21, 2010. 